\title{
Da cozinha ao hospital: Um pré-teste de comportamentos típicos de diferentes grupos profissionais
}

\author{
Margarida V. Garrido \\ Vera Soeiro \\ Tomás A. Palma \\ CIS/ISCTE - Instituto Universitário de Lisboa
}

\section{Resumo}

No presente artigo apresentam-se dois estudos com o objectivo de avaliar descrições de comportamentos típicos de seis grupos profissionais distintos: programador de computadores, trabalhador das obras, cozinheiro, médico, músico e agricultor. De um conjunto inicial de comportamentos gerados para cada grupo profissional por um grupo de 83 participantes, foram seleccionados 420 que foram avaliados por uma nova amostra de 122 participantes divididos em duas sub-amostras. Após a determinação de medidas de tendência central e intervalos de confiança a 95\%, os comportamentos foram ordenados de acordo com a sua média de tipicidade. As listas de comportamentos obtidas constituem um recurso para investigação futura em diversas áreas da psicologia nomeadamente nas áreas da cognição situada e corporalizada e da memória de acção.

Palavras-chave: Descrições comportamentais, Grupos profissionais, Normas, Tipicidade.

\begin{abstract}
This paper presents two studies that evaluate behavioral descriptions typical of six different professional groups: computer programmer, construction worker, cook, physician, musician, and farmer. From an initial pool of behaviors generated for each professional group by a sample of 83 participants, 420 behaviors were selected and rated by two new sub-samples of 122 participants. After calculating central tendency measures and confidence intervals at 95\% the behaviors were sorted according to their mean of typicality. The obtained lists of behaviors constitute a resource for future research in several fields of psychology such as situated and embodied cognition and action memory.

Key-words: Behavioral descriptions, Norms, Professional groups, Typicality.

A preparação deste artigo foi parcialmente apoiada por uma bolsa da Fundação para a Ciência e Tecnologia (PTDC/PSI/PSO/ /099346/2008), atribuída à primeira e último autor.

A correspondência relativa a este artigo deverá ser dirigida para: Margarida Vaz Garrido; Departamento de Psicologia Social e das Organizações, Escola de Ciências Sociais e Humanas, ISCTE - Instituto Universitário de Lisboa, Av. das Forças Armadas, 1649-026 Lisboa; E-mail: margarida.garrido@iscte.pt
\end{abstract}




\section{Introdução}

Uma parte substancial da investigação realizada no âmbito da formação de impressões e julgamento social utiliza paradigmas experimentais que geralmente implicam a apresentação de estímulos que caracterizam alvos sociais hipotéticos (e.g., informação geral sobre o alvo, traços de personalidade, descrições de comportamento, etc.). No entanto, e uma vez que a maioria da informação que adquirimos acerca dos nossos parceiros de interacção social se baseia na observação directa ou indirecta do seu comportamento (Srull, Lichtenstein, \& Rothbart, 1985), grande parte dos estudos realizados neste âmbito tem recorrido a descrições comportamentais como material estímulo. É a partir destes estímulos que os investigadores estudam o modo como os participantes nos estudos de formação de impressões (e supostamente o percipiente durante os processos quotidianos de percepção e interacção social) inferem traços, formam impressões de personalidade e a realizam julgamentos sociais, com o objectivo último de compreender como é que a informação social se organiza e se recupera a partir da memória (Fuhrman, Bodenhausen, \& Lichtenstein, 1989).

O presente estudo tem como objectivo produzir um conjunto de descrições comportamentais que complementem o material estímulo habitualmente utilizado em paradigmas de formação de impressões. Tradicionalmente, as descrições comportamentais testadas e utilizadas nos estudos de formação de impressões e de memória de pessoas incidem essencialmente em torno de dimensões-traço centrais e ortogonais como a simpatia ou a inteligência (Rosenberg, Nelson, \& Vivekananthan, 1968) relativamente inespecíficas face ao grupo social que caracterizam e relativamente abstractas face ao contexto em que ocorrem. A utilização destas dimensões tem-se mostrado eficaz no estabelecimento de impressões fortes possibilitando assim o estudo sistemático dos processos de formação de impressões e julgamento social (e.g., Garcia-Marques \& Hamilton, 1996; Hastie \& Kumar, 1979; Srull, 1981). No entanto, a utilização de apenas duas dimensões centrais é não só limitativa como por vezes a sua centralidade pode constranger determinados estudos experimentais (ver Garrido, Garcia-Marques, \& Jerónimo, 2004). No presente artigo, testamos um conjunto de descrições comportamentais características de outras dimensões menos centrais mas que, tal como as que têm vindo a ser utilizadas na literatura, constituam estímulos com base nos quais seja possível formar impressões de personalidade.

Por outro lado, a prevalência da utilização de dimensões centrais de personalidade tem-se feito acompanhar pela indução de expectativas convergentes com tais dimensões (e.g., Hamilton, 1986; Hamilton \& Zanna, 1974; Asch, 1946; Higgins \& Rholes, 1976; Schank, 1982; Srull et al., 1985; Zanna \& Hamilton, 1977). Embora a expectativa possa ser manipulada simplesmente através de instruções que indicam, por exemplo, o grau de simpatia ou inteligência da pessoa alvo (e.g., "tende a ser muito mais simpático do que a maioria das pessoas", "gosta de fazer novos amigos"), a maioria das investigações realizadas nesta área recorre, frequentemente, a grupos profissionais ou ocupacionais acerca dos quais a maioria das pessoas possui expectativas bem estabelecidas. Por exemplo, uma bibliotecária tende a ser estereotipicamente caracterizada como culta e aborrecida enquanto que uma empregada de mesa como inculta e divertida; um motorista de taxi é facilmente caracterizado como pouco ambicioso e divertido enquanto que um programador de computador tende a ser ambicioso mas aborrecido (ver GarciaMarques \& Hamilton, 1996). Um dos aspectos particularmente característicos quer dos grupos ocupacionais utilizados para induzir expectativas, quer das próprias descrições comportamentais que o participante deverá utilizar para formar a impressão, é a ausência de especificidade face a determinado estereótipo. Por exemplo, ao induzirmos uma expectativa de inteligência apresentando o alvo hipotético como matemático (e.g., Garcia-Marques, Hamilton, \& Maddox, 2002), poderíamos igualmente apresentá-lo como programador de computador, físico, professor universitário, entre outros. O conjunto 
de descrições comportamentais testadas no presente artigo envolvem espectativas mais específicas associadas a determinados grupos ocupacionais.

Finalmente, outra das características do material estímulo utilizado nos paradigmas tradicionais de formação de impressões é a natureza relativamente descontextualizada e descorporalizada das descrições comportamentais tipicamente apresentadas. Tais características do material estímulo, não pareceram constranger a investigação na área da memória de pessoas utilizando paradigmas e abordagens tradicionais (Anderson, 1965; Allport \& Allport, 1921; Asch, 1946; Hamilton, Katz, \& Leirer, 1980; Hastie, 1980; Srull, 1981). Note-se no entanto que, no âmbito destas abordagens, a percepção de pessoas é perspectivada como o desenvolvimento e manipulação de representações internas, assente no pressuposto implícito de que o conhecimento acerca dos outros reside num sistema de memória semântica dissociado de qualquer base sensorial e dos sistemas modais do cérebro para a percepção, acção e introspecção (e.g., Anderson \& Bower, 1973; Collins \& Loftus, 1975; Collins \& Quillian, 1969; Wyer \& Srull, 1989; ver Smith, 1998, para uma revisão). No entanto, propostas recentes sugerem que a cognição é constrangida pelas propriedades do nosso cérebro mas também do nosso corpo e do contexto envolvente e enfatizam a importância da simulação da experiência em sistemas de modalidades específicas (e.g., Barsalou, 1999, 2007, 2008; Glenberg, 2008; Smith \& Semin, 2004; Wilson, 2002; ver Semin, Garrido, \& Palma, 2011, para uma revisão). A adopção desta visão corporalizada e situada da percepção de pessoas sugere, assim, que a cognição, incluindo a de alto nível (Wilson, 2002), não depende só de abstracções amodais que existem independentemente do contexto, mas que, tal como em outros processos cognitivos, as impressões são estruturadas pela incorporação de elementos contextuais e sensório-motores (e.g., Palma, Garrido, \& Semin, 2011; Semin \& Garrido, 2011). Neste sentido, a realização de estudos no âmbito da memória de pessoas que adoptam uma abordagem situada da cognição, nomeadamente aqueles que exploram em que medida variáveis contextuais, tais como contextos físicos, objectos, acções ou movimentos corporais, são incorporadas na representação da pessoa, e facilitam ou dificultam o processo de formação de impressões e da sua recuperação mnésica, carecem de material estímulo mais específico. Neste sentido, para estudar o processo de formação de impressões no âmbito de uma abordagem situada da cognição é necessário o desenvolvimento de material estímulo. Designadamente, descrições comportamentais que sejam mais específicas do grupo profissional/ocupacional apresentado fazendo referência a situações e tarefas do alvo e ainda incluir objectos, utensílios ou ferramentas que ilustrem o contexto no qual estas acções são executadas.

É com base nestes argumentos que apresentamos neste artigo uma lista de 420 descrições comportamentais de seis grupos profissionais distintos. Estes comportamentos foram gerados num primeiro estudo por um grupo de participantes e subsequentemente avaliados, num segundo estudo, por um outro grupo independente quanto à sua tipicidade em relação à profissão em questão.

\title{
ESTUDO 1
}

\author{
Método \\ Participantes \\ Participaram neste estudo 83 estudantes universitários do ISCTE - Instituto Universitário de Lisboa e \\ da Faculdade de Psicologia da Universidade de Lisboa (81 mulheres, idade $M=20.64 ; D P=1.83$ ).
}




\section{Procedimento}

Os 83 participantes foram solicitados a gerar 6 comportamentos considerados típicos das profissões de programador de computadores, trabalhador de obras, cozinheiro, médico, músico e agricultor. Especificamente, foi pedido aos participantes para pensarem livremente, no tipo de comportamentos que estes profissionais têm no dia-a-dia durante a realização do seu trabalho. No entanto, e para que os comportamentos gerados fossem verdadeiramente específicos destas profissões os participantes deveriam ter em atenção dois aspectos: (1) que para realizar o seu trabalho estas pessoas executam acções específicas e muitas vezes utilizam equipamentos, ferramentas e utensílios; neste sentido, deveriam procurar incluir, nos comportamentos gerados, acções que envolvam esses equipamentos, ferramentas e utensílios e também acções que não os envolvam; (2) que durante o trabalho as pessoas fazem algumas coisas bem e outras mal e neste sentido, deveriam procurar incluir comportamentos que indiquem acções quer positivas quer negativas destes profissionais. Seguia-se um exemplo de 4 comportamentos do "cozinheiro", um positivo e um negativo envolvendo utensílios (e.g., "Usou uma faca japonesa para que o peixe ficasse bem fininho", "Deixou queimar o refogado e estragou o fundo do tacho") e um positivo e um negativo não envolvendo utensílios (e.g., "Pensou no que ia preparar para o jantar", "Deixou queimar o refogado").

\section{Resultados}

Os comportamentos gerados pelos participantes foram sujeitos a um processo de eliminação de redundâncias, e posteriormente seleccionados por 3 juízes independentes de acordo com os seguintes critérios: (a) serem descritivos da profissão em causa; (b) constituírem descrições comportamentais de valência positiva ou negativa, (c) mencionarem na sua maioria o manuseamento específico de equipamentos, ferramentas e utensílios diversos, (d) apresentarem uma dimensão homogénea, por forma a controlar variáveis como a rapidez de leitura e de recordação (o tamanho das frases, embora nem sempre igual, nunca excedeu uma linha). Após esta análise foram seleccionados 420 comportamentos. Estes comportamentos foram posteriormente avaliados quanto ao seu grau de tipicidade face a 6 grupos ocupacionais tal como descrito no Estudo 2.

\section{ESTUDO 2}

\section{Método}

\section{Participantes}

Participaram neste estudo 122 estudantes universitários do ISCTE - Instituto Universitário de Lisboa e da Faculdade de Psicologia da Universidade de Lisboa (94 mulheres, idade $M=25.02 ; D P=8.15$ ).

\section{Material estímulo}

Os 420 comportamentos seleccionados no Estudo 1 foram distribuídos por 6 listas, cada uma delas correspondendo a um dos 6 grupos ocupacionais. Cada lista foi assim constituída por 70 comportamentos (35 comportamentos típicos positivos e 35 comportamentos típicos negativos) apresentados de forma intercalada em cada lista. 


\section{Procedimento}

As listas de comportamentos foram organizadas em dois conjuntos distintos com 3 grupos ocupacionais cada, e avaliadas separadamente por dois grupos de participantes $(N=64$ e $N=58)$ com vista a evitar o cansaço e desinteresse que poderiam resultar da avaliação da totalidade das listas. Assim 64 participantes receberam um caderno constituído por três listas de comportamentos típicos, correspondentes às profissões de programador de computadores, trabalhador de obras e cozinheiro; e outros 58 participantes receberam um caderno constituído por três listas de comportamentos típicos das restantes profissões, designadamente médico, músico e agricultor.

As instruções apresentadas aos participantes no início de cada uma das listas solicitavam que estes indicassem em que medida consideravam típicos da respectiva profissão-alvo os comportamentos apresentados. Ao lado de cada comportamento era apresentada uma escala de 9 pontos, na qual os participantes deveriam assinalar o número que melhor correspondia à sua avaliação de tipicidade do comportamento, face à profissão-alvo em questão. Nesta escala, 1 correspondia à avaliação do comportamento como "nada típico" da profíssão-alvo em causa (e.g., nada típico de um programador de computadores) e 9 a um comportamento "muito típico" da profissão-alvo em causa (e.g., muito típico de um programador de computadores). Os participantes demoraram cerca de 30 minutos a completar a tarefa.

\section{Resultados}

Para as avaliações de tipicidade das descrições comportamentais de cada grupo profissional apresentamos a média (que nos indica o valor central da distribuição das avaliações de cada comportamento), o desvio-padrão (para determinar em que medida as avaliações realizadas para cada comportamento são, ou não, consensuais) e os intervalos de confiança a $95 \%$ associados às médias (que permitem o teste de hipóteses relativas à existência de diferenças significativas entre as médias).

O cálculo dos intervalos de confiança de $95 \%$ foi realizado por forma a identificar os comportamentos de cada ocupação profissional com avaliações de tipicidade significativamente diferentes do ponto médio da escala, que neste caso é 5 . Assim, se a média estiver acima do ponto 5 e se o limite inferior do intervalo de confiança não contiver este valor podemos inferir com $95 \%$ de confiança que determinado comportamento é considerado pela nossa amostra como típica da profissão em causa. Por outro lado, se a média se encontrar abaixo do ponto 5 e o limite superior do intervalo de confiança não incluir este valor, conclui-se que determinado comportamento é considerado pouco típica do grupo profissional em questão. Se o intervalo de confiança contiver o ponto 5 não podemos inferir com confiança que o comportamento é considerado muito ou pouco típico do grupo profissional.

De seguida apresentamos toda a informação relativa às descrições comportamentais e às suas avaliações. Esta informação encontra-se organizada por grupo profissional e ordenada de forma decrescente segundo os seus valores médios de tipicidade. De forma a facilitar a selecção dos comportamentos considerados mais típicos de determinado grupo profissional, assinalaram-se a negrito aqueles cujo intervalo de confiança não inclui o ponto médio da escala.

Com base num critério bastante abrangente (mera exclusão do ponto médio do intervalo de confiança) os resultados destas análises permitiram identificar 35 comportamentos típicos de programadores de computadores, 40 de trabalhadores das obras, 34 de cozinheiros; 38 de médicos; 30 de músicos e 40 de agricultores. 
Quadro 1

Resultados obtidos na profissão Programador de Computadores

\begin{tabular}{|c|c|c|c|c|c|}
\hline \multirow[b]{3}{*}{ Descrição comportamental } & \multicolumn{5}{|c|}{ Programador de Computadores } \\
\hline & \multicolumn{5}{|c|}{ Int. conf. $95 \%$} \\
\hline & $N$ & $M$ & $L I$ & $L S$ & $D P$ \\
\hline Tecla muito rapidamente. & 64 & 7,84 & 7,39 & 8,30 & 1,836 \\
\hline Sabe de cor todos os atalhos que se podem executar no teclado. & 64 & 7,78 & 7,38 & 8,19 & 1,618 \\
\hline Formatou o computador e instalou os programas necessários. & 64 & 7,73 & 7,30 & 8,16 & 1,720 \\
\hline Instalou um antivírus no computador. & 64 & 7,64 & 7,21 & 8,07 & 1,712 \\
\hline Copiou toda a informação necessária para um disco externo. & 64 & 7,58 & 7,10 & 8,06 & 1,917 \\
\hline Procedeu à remoção de um vírus fatal. & 64 & 7,41 & 7,03 & 7,78 & 1,498 \\
\hline Verificou se os cabos estavam todos bem ligados. & 64 & 7,31 & 6,91 & 7,72 & 1,622 \\
\hline Instalou software num computador do seu cunhado. & 64 & 7,30 & 6,85 & 7,74 & 1,788 \\
\hline Consegue aceder remotamente a computadores pessoais e servidores de empresas. & 63 & 7,29 & 6,82 & 7,75 & 1,835 \\
\hline Actualiza-se diariamente acerca de novos produtos informáticos. & 64 & 7,22 & 6,79 & 7,65 & 1,723 \\
\hline Utiliza dois ou mais computadores simultaneamente. & 64 & 7,20 & 6,75 & 7,66 & 1,819 \\
\hline Programou e organizou as siglas e passwords dos diferentes departamentos. & 63 & 7,19 & 6,73 & 7,65 & 1,813 \\
\hline Recuperou um trabalho de um colega que este achava perdido para sempre. & 64 & 7,16 & 6,69 & 7,62 & 1,871 \\
\hline Assistiu a um workshop sobre programação. & 64 & 7,14 & 6,61 & 7,67 & 2,107 \\
\hline Comprou um modelo de computador mais recente. & 64 & 7,14 & 6,64 & 7,65 & 2,023 \\
\hline As longas horas em frente ao computador já lhe garantiram um par de óculos. & 64 & 7,09 & 6,66 & 7,53 & 1,752 \\
\hline Preparou um CD de instalação de um programa sofisticado. & 64 & 7,05 & 6,56 & 7,53 & 1,939 \\
\hline Anda sempre com um computador consigo. & 63 & 7,03 & 6,52 & 7,55 & 2,048 \\
\hline Configurou a internet num computador. & 63 & 7,02 & 6,55 & 7,48 & 1,853 \\
\hline Fala com uma linguagem técnica que poucas pessoas entendem. & 63 & 6,97 & 6,53 & 7,41 & 1,759 \\
\hline Gravou os dados numa pen (USB). & 64 & 6,69 & 6,16 & 7,21 & 2,107 \\
\hline Reiniciou o modem para testar a ligação à internet. & 64 & 6,67 & 6,14 & 7,20 & 2,116 \\
\hline Desenhou uma página da internet muito sofisticada. & 63 & 6,65 & 6,12 & 7,18 & 2,111 \\
\hline Jogou um jogo durante o horário de trabalho. & 64 & 6,45 & 5,96 & 6,94 & 1,959 \\
\hline Fez downloads ilegais de filmes e de música. & 64 & 6,41 & 5,91 & 6,90 & 1,974 \\
\hline Conseguiu resolver o problema da ventoinha do computador. & 64 & 6,38 & 5,89 & 6,86 & 1,956 \\
\hline Acha que o seu computador comprado há 6 meses já é obsoleto. & 64 & 6,14 & 5,63 & 6,66 & 2,061 \\
\hline Estudou álgebra antes de programar. & 64 & 6,11 & 5,53 & 6,69 & 2,338 \\
\hline Por vezes sofre de dores de cabeça. & 64 & 6,11 & 5,61 & 6,61 & 1,985 \\
\hline Criou e programou um jogo de cartas para adultos. & 64 & 5,92 & 5,31 & 6,53 & 2,451 \\
\hline Imprimiu os documentos numa impressora a laser. & 64 & 5,88 & 5,36 & 6,39 & 2,059 \\
\hline Irrita-se muito se alguém toca com os dedos no seu monitor. & 64 & 5,66 & 5,10 & 6,21 & 2,213 \\
\hline Copiou um DVD sem permissão. & 64 & 5,66 & 5,11 & 6,21 & 2,205 \\
\hline Comprou um tapete ergonómico para o rato do computador. & 64 & 5,61 & 5,06 & 6,16 & 2,187 \\
\hline Colocou os tinteiros na impressora. & 64 & 5,58 & 5,00 & 6,15 & 2,301 \\
\hline É pouco sociável, porque passa muito tempo em frente ao computador. & 64 & 5,50 & 5,04 & 5,96 & 1,860 \\
\hline Proferiu uma conferência sobre sistemas informáticos remotos. & 64 & 5,42 & 4,87 & 5,97 & 2,210 \\
\hline Utilizou uma chave de parafusos para tirar a motherboard do computador. & 64 & 5,11 & 4,56 & 5,66 & 2,212 \\
\hline Não conseguiu terminar o programa no devido prazo. & 64 & 5,02 & 4,54 & 5,50 & 1,923 \\
\hline Constatou que a caixa de CD's estava praticamente vazia. & 64 & 5,00 & 4,43 & 5,57 & 2,282 \\
\hline Scanarizou os manuais de um programa estatístico. & 64 & 4,98 & 4,43 & 5,54 & 2,215 \\
\hline Tornou-se viciado em redes sociais. & 64 & 4,86 & 4,35 & 5,37 & 2,030 \\
\hline Escreveu um livro sobre programação de ambientes de realidade virtual. & 63 & 4,86 & 4,31 & 5,41 & 2,191 \\
\hline Fala com o computador como se este fosse um ser humano. & 63 & 4,86 & 4,27 & 5,45 & 2,348 \\
\hline
\end{tabular}




\begin{tabular}{|c|c|c|c|c|c|}
\hline \multirow[b]{3}{*}{ Descrição comportamental } & \multicolumn{5}{|c|}{ Programador de Computadores } \\
\hline & \multicolumn{5}{|c|}{ Int. conf. $95 \%$} \\
\hline & $N$ & $M$ & $L I$ & $L S$ & $D P$ \\
\hline Assumiu ser um especialista de informática mas não resolveu bem o problema. & 64 & 4,75 & 4,21 & 5,29 & 2,160 \\
\hline Não usa Macintosh na empresa. & 64 & 4,70 & 4,27 & 5,14 & 1,743 \\
\hline Tem o teclado cheio de migalhas. & 64 & 4,61 & 4,12 & 5,10 & 1,957 \\
\hline Verificou que os DVD’s que tinha não eram regraváveis. & 64 & 4,59 & 4,07 & 5,12 & 2,106 \\
\hline Está sempre com os auscultadores e por isso não ouve ninguém. & 64 & 4,31 & 3,82 & 4,81 & 1,975 \\
\hline Criou um vírus para destruir todos os programas do computador. & 63 & 4,08 & 3,56 & 4,60 & 2,066 \\
\hline Esqueceu-se do seu kit de pequenas ferramentas. & 64 & 3,75 & 3,37 & 4,13 & 1,533 \\
\hline Deixou cair o seu computador portátil ao chão. & 64 & 3,64 & 3,12 & 4,17 & 2,103 \\
\hline Não levou ferramenta adequada para montar a placa gráfica. & 64 & 3,63 & 3,18 & 4,07 & 1,795 \\
\hline Bateu três vezes no monitor porque este bloqueou. & 64 & 3,56 & 3,06 & 4,06 & 1,999 \\
\hline Entornou um copo de sumo no CPU do computador. & 64 & 3,45 & 3,01 & 3,90 & 1,781 \\
\hline Não conseguiu recuperar todos os dados de um disco rígido. & 64 & 3,42 & 2,93 & 3,91 & 1,958 \\
\hline Usou um alicate para cortar o cabo da internet que era demasiado comprido. & 64 & 3,34 & 2,78 & 3,91 & 2,262 \\
\hline Tanto mexeu nos cabos que queimou o transformador do computador. & 64 & 3,28 & 2,83 & 3,73 & 1,804 \\
\hline Atirou o rato ao chão porque se irritou com o colega. & 64 & 3,17 & 2,72 & 3,63 & 1,822 \\
\hline Formatou o computador e inadvertidamente apagou a informação do disco rígido. & 63 & 3,06 & 2,63 & 3,50 & 1,740 \\
\hline Utilizou o cabo danificado o qual provocou um curto-circuito. & 64 & 2,98 & 2,60 & 3,37 & 1,538 \\
\hline Enganou-se no carregador da bateria e acabou por estragá-la. & 64 & 2,86 & 2,50 & 3,22 & 1,446 \\
\hline Esqueceu-se de fazer back-up dos ficheiros para o disco externo. & 64 & 2,84 & 2,48 & 3,21 & 1,461 \\
\hline Desmontou e montou o computador mas sobraram montes de peças. & 64 & 2,83 & 2,42 & 3,24 & 1,648 \\
\hline Atirou com o microfone à parede porque não o conseguia pôr a funcionar. & 64 & 2,80 & 2,37 & 3,22 & 1,711 \\
\hline Ao programar um computador de um cliente passou um vírus fatal. & 64 & 2,72 & 2,33 & 3,10 & 1,538 \\
\hline Tanto mexeu que deu cabo das colunas do computador. & 64 & 2,64 & 2,28 & 3,00 & 1,452 \\
\hline De tanto tentar focar a imagem partiu a webcam. & 64 & 2,56 & 2,14 & 2,98 & 1,680 \\
\hline Inseriu o CD errado na drive e estragou ou computador. & 64 & 2,56 & 2,15 & 2,97 & 1,641 \\
\hline Encravou a impressora porque pôs papel a mais. & 64 & 2,41 & 2,06 & 2,75 & 1,388 \\
\hline
\end{tabular}

Nota. Comportamentos a negrito são típicos de Programador de computadores para $95 \%$ de confiança; $N$ (número de respostas), $M$ (média da avaliação), DP (desvio padrão), $L I$ (limite inferior), $L S$ (limite superior).

Quadro 2

Resultados obtidos na profissão Trabalhador de Obras

\begin{tabular}{|c|c|c|c|c|c|}
\hline \multirow[b]{3}{*}{ Descrição comportamental } & \multicolumn{5}{|c|}{ Trabalhador das Obras } \\
\hline & \multicolumn{5}{|c|}{ Int. conf. $95 \%$} \\
\hline & $N$ & $M$ & $L I$ & $L S$ & $D P$ \\
\hline Carregou baldes de água para fazer cimento. & 64 & 7,89 & 7,55 & 8,23 & 1,347 \\
\hline Utilizou o martelo para pregar o prego. & 64 & 7,77 & 7,36 & 8,17 & 1,621 \\
\hline Transporta materiais de construção com um carrinho de mão. & 63 & 7,75 & 7,42 & 8,07 & 1,295 \\
\hline Transpirou bastante naquele dia. & 64 & 7,73 & 7,44 & 8,03 & 1,198 \\
\hline Carregou com dois sacos de areia. & 64 & 7,70 & 7,29 & 8,12 & 1,649 \\
\hline Levanta-se sempre muito cedo para ir trabalhar. & 64 & 7,69 & 7,39 & 7,99 & 1,194 \\
\hline Fez um balde de massa para aplicar nas paredes. & 64 & 7,56 & 7,17 & 7,96 & 1,572 \\
\hline Colocou massa na parede para tapar os buracos com uma espátula. & 64 & 7,45 & 7,04 & 7,87 & 1,661 \\
\hline Gosta de beber a sua cervejinha para refrescar. & 64 & 7,45 & 7,07 & 7,84 & 1,532 \\
\hline
\end{tabular}


$(\leftarrow$ cont.

\begin{tabular}{|c|c|c|c|c|c|}
\hline \multirow[b]{3}{*}{ Descrição comportamental } & \multicolumn{5}{|c|}{ Trabalhador das Obras } \\
\hline & \multicolumn{5}{|c|}{ Int. conf. $95 \%$} \\
\hline & $N$ & $M$ & $L I$ & $L S$ & $D P$ \\
\hline De manhã levou os baldes e pás para a carrinha para seguir para a obra. & 63 & 7,41 & 7,00 & 7,83 & 1,652 \\
\hline Chegou a casa com a roupa suja, manchada. & 63 & 7,41 & 6,92 & 7,90 & 1,948 \\
\hline Usa uma caixa própria para transportar ferramentas. & 64 & 7,27 & 6,87 & 7,66 & 1,576 \\
\hline Fala alto, por cima do ruído das máquinas. & 64 & 7,11 & 6,74 & 7,48 & 1,481 \\
\hline Utilizou o pincel para que os cantos da parede ficassem bem pintados. & 64 & 7,02 & 6,50 & 7,53 & 2,051 \\
\hline Assentou bem os azulejos da casa de banho. & 64 & 6,91 & 6,49 & 7,32 & 1,659 \\
\hline Usou a pá para encher uma vala de areia. & 64 & 6,91 & 6,48 & 7,33 & 1,697 \\
\hline Tem pouca escolaridade. & 63 & 6,90 & 6,53 & 7,28 & 1,500 \\
\hline Saiu de casa para a obra com a sua roupa de trabalho. & 64 & 6,88 & 6,36 & 7,39 & 2,082 \\
\hline Operou a grua com concentração e cuidado. & 64 & 6,83 & 6,44 & 7,21 & 1,549 \\
\hline Sofre de dores na coluna e musculares. & 64 & 6,83 & 6,40 & 7,26 & 1,733 \\
\hline Reparou uma telha partida. & 64 & 6,81 & 6,34 & 7,29 & 1,901 \\
\hline Antes de pintar colocou fita adesiva em volta da janela. & 64 & 6,81 & 6,27 & 7,36 & 2,174 \\
\hline Pintou uma parede com tinta azul usando o rolo mais largo. & 64 & 6,81 & 6,40 & 7,22 & 1,641 \\
\hline Não terminou a obra no tempo estabelecido. & 63 & 6,76 & 6,31 & 7,21 & 1,793 \\
\hline Mandou piropos às mulheres que passavam. & 63 & 6,73 & 6,30 & 7,16 & 1,725 \\
\hline Usou uma chave de parafusos para fixar a porta do roupeiro. & 64 & 6,61 & 6,13 & 7,09 & 1,908 \\
\hline Subiu ao escadote para colocar melhor o prego. & 64 & 6,52 & 6,05 & 6,98 & 1,852 \\
\hline Reforçou a estrutura com arame para ficar mais sólida. & 63 & 6,51 & 6,09 & 6,92 & 1,655 \\
\hline Usou uma chave-inglesa para apertar as porcas da canalização. & 63 & 6,41 & 5,87 & 6,95 & 2,153 \\
\hline Deu ordem para que o betão fosse descarregado do camião. & 64 & 6,38 & 5,93 & 6,82 & 1,768 \\
\hline Utiliza capacete na obra para se proteger. & 64 & 6,34 & 5,82 & 6,87 & 2,087 \\
\hline Fez medições cuidadosas antes de começar usando a fita métrica. & 64 & 6,20 & 5,78 & 6,62 & 1,683 \\
\hline Calçou as botas adequadas para entrar no terreno. & 64 & 6,16 & 5,72 & 6,59 & 1,739 \\
\hline Andou toda a manhã a conduzir a retro-escavadora. & 64 & 6,14 & 5,71 & 6,57 & 1,726 \\
\hline Usou a picareta para fazer um buraco para a canalização. & 64 & 6,14 & 5,67 & 6,61 & 1,893 \\
\hline Utilizou dois baldes para transportar tinta. & 64 & 6,05 & 5,58 & 6,51 & 1,855 \\
\hline Consertou as dobradiças de uma porta com um alicate. & 64 & 5,88 & 5,36 & 6,39 & 2,074 \\
\hline Aleijou-se ao pregar umas tábuas na parede. & 64 & 5,73 & 5,27 & 6,20 & 1,871 \\
\hline Seguiu à risca o projecto da obra proposto pelo arquitecto. & 63 & 5,60 & 5,19 & 6,02 & 1,651 \\
\hline Cortou-se num tijolo porque não usou luvas para se proteger. & 64 & 5,58 & 5,13 & 6,02 & 1,789 \\
\hline Usou óculos de protecção para se proteger de poeiras e faúlhas. & 64 & 5,44 & 4,89 & 5,98 & 2,174 \\
\hline Usa protecções nos ouvidos quando utiliza a motosserra. & 64 & 5,42 & 4,86 & 5,98 & 2,231 \\
\hline Não usou o colete de protecção. & 63 & 5,35 & 4,81 & 5,89 & 2,141 \\
\hline Envernizou o chão com um verniz e um pincel. & 64 & 5,20 & 4,60 & 5,80 & 2,405 \\
\hline Arranjou uma porta que estava partida com a ajuda de um serrote. & 64 & 5,06 & 4,54 & 5,58 & 2,085 \\
\hline Não limpou bem a espátula. & 64 & 5,02 & 4,54 & 5,49 & 1,915 \\
\hline Quando trabalha em andaimes utiliza cordas para sua segurança. & 63 & 4,95 & 4,42 & 5,48 & 2,098 \\
\hline Caiu de um andaime e partiu uma perna. & 63 & 4,89 & 4,42 & 5,36 & 1,859 \\
\hline Subiu o andaime sem as protecções necessárias. & 64 & 4,83 & 4,37 & 5,28 & 1,822 \\
\hline Não cumpriu as ordens do empreiteiro. & 63 & 4,65 & 4,22 & 5,08 & 1,696 \\
\hline Caiu de um escadote enquanto estava a montar uma janela. & 63 & 4,41 & 4,01 & 4,82 & 1,603 \\
\hline Deixou cair do andaime um balde com entulho. & 64 & 4,41 & 3,93 & 4,89 & 1,925 \\
\hline Deixou cair um tijolo no pé. & 64 & 4,25 & 3,59 & 4,91 & 2,655 \\
\hline Martelou um prego no sítio errado da casa. & 64 & 4,17 & 3,75 & 4,59 & 1,686 \\
\hline Mediu mal o comprimento e por isso o cimento para rebocar a parede não chegou. & 64 & 4,14 & 3,72 & 4,56 & 1,698 \\
\hline
\end{tabular}




\begin{tabular}{|c|c|c|c|c|c|}
\hline \multirow[b]{3}{*}{ Descrição comportamental } & \multicolumn{5}{|c|}{ Trabalhador das Obras } \\
\hline & \multicolumn{5}{|c|}{ Int. conf. $95 \%$} \\
\hline & $N$ & $M$ & $L I$ & $L S$ & $D P$ \\
\hline Não colocou bem o cimento. & 64 & 4,13 & 3,75 & 4,50 & 1,485 \\
\hline Tropeçou num balde de tinta e espalhou-a pelo chão. & 64 & 3,91 & 3,44 & 4,37 & 1,875 \\
\hline Não misturou bem os constituintes do cimento. & 64 & 3,83 & 3,44 & 4,22 & 1,559 \\
\hline Colocou os azulejos na divisão errada. & 64 & 3,78 & 3,36 & 4,20 & 1,676 \\
\hline Não usou capacete de protecção e foi atingido por um tijolo. & 64 & 3,72 & 3,30 & 4,13 & 1,657 \\
\hline Falhou na instalação dos percursos de canalização da casa. & 64 & 3,70 & 3,33 & 4,08 & 1,508 \\
\hline Deixou cair um saco de cimento do $3^{\mathrm{o}}$ andar. & 64 & 3,66 & 3,17 & 4,14 & 1,945 \\
\hline Não calçou as botas próprias para as obras e passou o dia a escorregar. & 62 & 3,60 & 3,19 & 4,00 & 1,583 \\
\hline Estava a pintar a parede e caiu-lhe o balde de tinta em cima. & 63 & 3,59 & 3,17 & 4,01 & 1,662 \\
\hline Estava a trabalhar com o berbequim e furou um dedo. & 64 & 3,45 & 3,03 & 3,88 & 1,699 \\
\hline Pintou o muro de uma casa da cor errada. & 64 & 3,28 & 2,92 & 3,64 & 1,431 \\
\hline Viu mal a planta e construiu uma parede no sítio errado. & 63 & 3,06 & 2,65 & 3,48 & 1,655 \\
\hline Deixou que as faíscas do trabalho com o maçarico caíssem em liquido inflamável. & 64 & 3,06 & 2,66 & 3,47 & 1,612 \\
\hline Deixou cair um martelo em cima da cabeça de outro trabalhador. & 64 & 2,94 & 2,54 & 3,34 & 1,592 \\
\hline Queimou o circuito eléctrico do edifício. & 64 & 2,84 & 2,50 & 3,19 & 1,394 \\
\hline
\end{tabular}

Nota. Comportamentos a negrito são típicos de Trabalhador das obras para $95 \%$ de confiança; $N$ (número de respostas), $M$ (média da avaliação), $D P$ (desvio padrão), $L I$ (limite inferior), $L S$ (limite superior).

Quadro 3

Resultados obtidos na profissão Cozinheiro

\begin{tabular}{|c|c|c|c|c|c|}
\hline \multirow[b]{3}{*}{ Descrição comportamental } & \multicolumn{5}{|c|}{ Cozinheiro } \\
\hline & \multicolumn{5}{|c|}{ Int. conf. $95 \%$} \\
\hline & $N$ & $M$ & $L I$ & $L S$ & $D P$ \\
\hline Consegue preparar diversos tipos de comida. & 64 & 8,27 & 8,02 & 8,51 & ,980 \\
\hline Acendeu o fogão para tratar do almoço. & 64 & 8,06 & 7,72 & 8,41 & 1,379 \\
\hline Decora as travessas antes delas irem para a mesa. & 64 & 7,58 & 7,16 & 8,00 & 1,670 \\
\hline Utilizou a colher de pau para mexer o molho. & 63 & 7,52 & 7,07 & 7,97 & 1,786 \\
\hline Colocou o chapéu e prendeu o cabelo quando entrou na cozinha. & 64 & 7,52 & 7,20 & 7,83 & 1,247 \\
\hline Untou bem o tabuleiro com margarina. & 64 & 7,48 & 7,16 & 7,81 & 1,297 \\
\hline Usou a espátula para alisar a cobertura do bolo de chocolate. & 64 & 7,42 & 7,05 & 7,80 & 1,499 \\
\hline Utilizou vários condimentos que retirou de pequenos frascos. & 64 & 7,39 & 7,01 & 7,77 & 1,529 \\
\hline Foi buscar os ingredientes ao frigorífico. & 64 & 7,38 & 6,93 & 7,82 & 1,768 \\
\hline Abriu uma garrafa de vinho com toda a facilidade. & 64 & 7,36 & 6,94 & 7,78 & 1,665 \\
\hline Todos elogiaram a refeição que ele preparou. & 64 & 7,36 & 7,02 & 7,70 & 1,350 \\
\hline Corta os vegetais em cima de uma tábua de cozinha. & 64 & 7,28 & 6,91 & 7,65 & 1,496 \\
\hline Utilizou uma frigideira para estrelar ovos. & 64 & 7,23 & 6,81 & 7,66 & 1,688 \\
\hline Utilizou uma colher para provar o molho. & 63 & 7,19 & 6,80 & 7,58 & 1,544 \\
\hline Ralou a cenoura bem fininha. & 64 & 7,13 & 6,70 & 7,55 & 1,686 \\
\hline Tirou o bolo de chocolate da forma. & 64 & 7,11 & 6,66 & 7,55 & 1,783 \\
\hline Lavou e escorreu a salada. & 64 & 7,08 & 6,64 & 7,52 & 1,758 \\
\hline Afiou as facas antes de cortar a carne. & 64 & 6,98 & 6,45 & 7,52 & 2,149 \\
\hline Bateu as natas com a batedeira. & 64 & 6,94 & 6,42 & 7,45 & 2,062 \\
\hline Elaborou uma lista de ingredientes que precisava para preparar a refeição. & 64 & 6,92 & 6,42 & 7,43 & 2,026 \\
\hline
\end{tabular}




\begin{tabular}{|c|c|c|c|c|c|}
\hline \multirow[b]{3}{*}{ Descrição comportamental } & \multicolumn{5}{|c|}{ Cozinheiro } \\
\hline & \multicolumn{5}{|c|}{ Int. conf. $95 \%$} \\
\hline & $N$ & $M$ & $L I$ & $L S$ & $D P$ \\
\hline Pesou o açúcar numa balança muito precisa. & 64 & 6,91 & 6,42 & 7,39 & 1,950 \\
\hline Picou a carne na trituradora. & 64 & 6,80 & 6,34 & 7,25 & 1,819 \\
\hline Sujou o avental com molho de tomate. & 64 & 6,72 & 6,29 & 7,14 & 1,704 \\
\hline Descascou e cortou as batatas em rodelas. & 64 & 6,69 & 6,23 & 7,15 & 1,842 \\
\hline Bateu a sopa com uma varinha mágica. & 64 & 6,58 & 6,07 & 7,09 & 2,046 \\
\hline Utilizou o garfo para retirar o pedaço de carne da panela. & 64 & 6,48 & 6,01 & 6,96 & 1,919 \\
\hline Cortou o pão com um a faca de serra. & 63 & 6,40 & 5,84 & 6,96 & 2,226 \\
\hline Pôs a água a ferver numa cafeteira. & 64 & 6,22 & 5,70 & 6,74 & 2,081 \\
\hline Utilizou um martelo para "espalmar" bem a carne de modo a ficar mais tenra. & 64 & 6,20 & 5,62 & 6,79 & 2,351 \\
\hline Serviu a sopa com uma concha de prata. & 64 & 5,98 & 5,41 & 6,56 & 2,299 \\
\hline Cronometrou o tempo para o arroz ficar cozido. & 64 & 5,89 & 5,27 & 6,51 & 2,489 \\
\hline Ralou o queijo até este ficar quase em pó. & 64 & 5,83 & 5,27 & 6,39 & 2,244 \\
\hline As suas panelas estão sempre a brilhar. & 64 & 5,80 & 5,34 & 6,26 & 1,845 \\
\hline Consultou um livro de receitas. & 64 & 5,73 & 5,21 & 6,26 & 2,087 \\
\hline Usou um funil para deitar a limonada na garrafa. & 62 & 5,44 & 4,88 & 5,99 & 2,178 \\
\hline Deixou uma montanha de pratos sujos para o colega lavar. & 64 & 5,11 & 4,60 & 5,62 & 2,056 \\
\hline Lavou os tachos com a ajuda do colega. & 64 & 4,64 & 4,11 & 5,17 & 2,133 \\
\hline Chorou ao cortar cebolas. & 64 & 4,44 & 3,92 & 4,96 & 2,085 \\
\hline Queimou-se a tirar um prato do forno. & 64 & 4,19 & 3,65 & 4,73 & 2,167 \\
\hline Deixou cair a colher dentro da sopa. & 64 & 4,16 & 3,62 & 4,69 & 2,147 \\
\hline Queimou-se com óleo que espirrou da frigideira. & 64 & 4,05 & 3,58 & 4,51 & 1,864 \\
\hline Moeu pimenta preta em vez de pimenta verde. & 64 & 3,91 & 3,43 & 4,39 & 1,917 \\
\hline Cortou o dedo enquanto cortava batatas. & 64 & 3,63 & 3,19 & 4,06 & 1,750 \\
\hline Deixou queimar as pegas no lume do fogão. & 64 & 3,61 & 3,04 & 4,18 & 2,272 \\
\hline Esqueceu-se de colocar a touca na cabeça. & 64 & 3,58 & 3,14 & 4,01 & 1,735 \\
\hline Cortou-se ao abrir uma lata de leite condensado. & 64 & 3,53 & 3,08 & 3,99 & 1,817 \\
\hline Colocou demasiado sal na comida. & 64 & 3,38 & 2,96 & 3,79 & 1,667 \\
\hline Não conseguiu desenformar o bolo em condições. & 64 & 3,28 & 2,87 & 3,70 & 1,657 \\
\hline Não colocou sal suficiente e a comida ficou sem sabor. & 64 & 3,27 & 2,86 & 3,67 & 1,635 \\
\hline Deixou o molho agarrar ao fundo do tacho. & 64 & 3,17 & 2,77 & 3,58 & 1,619 \\
\hline Deixou cair o tacho com comida. & 64 & 3,17 & 2,78 & 3,56 & 1,559 \\
\hline Deixou a panela ao lume tempo demais e cozeu demasiado a massa. & 64 & 3,11 & 2,72 & 3,50 & 1,554 \\
\hline Deixou ficar as torradas tempo demais na torradeira. & 64 & 3,11 & 2,78 & 3,44 & 1,311 \\
\hline Esqueceu-se de comprar hortaliças frescas. & 64 & 3,11 & 2,68 & 3,53 & 1,701 \\
\hline Deixou que o soufflé viesse todo a baixo. & 64 & 3,11 & 2,72 & 3,50 & 1,554 \\
\hline Deixou as batatas fritas tempo de mais na fritadeira & 64 & 3,06 & 2,66 & 3,46 & 1,592 \\
\hline Deixou cair o tabuleiro de lasanha ao chão quando o retirava do forno. & 64 & 3,05 & 2,64 & 3,46 & 1,647 \\
\hline Usou um tacho pequeno num bico grande do fogão e queimou-o por fora. & 64 & 3,02 & 2,57 & 3,47 & 1,804 \\
\hline Não amassou bem a massa do pão. & 64 & 2,97 & 2,63 & 3,31 & 1,357 \\
\hline Esqueceu-se da comida ao lume e deixou-a queimar. & 64 & 2,95 & 2,60 & 3,30 & 1,396 \\
\hline Deixou o forno desligado e a comida não aqueceu. & 64 & 2,84 & 2,50 & 3,19 & 1,383 \\
\hline Não enfarinhou o rolo antes de estender a massa dos croissants. & 64 & 2,77 & 2,40 & 3,13 & 1,466 \\
\hline Espirrou para dentro da panela onde aquecia a sopa. & 63 & 2,67 & 2,33 & 3,00 & 1,332 \\
\hline Deixou as batatas apodrecerem. & 64 & 2,61 & 2,24 & 2,98 & 1,497 \\
\hline Derreteu uma caixa plástica com comida no microondas. & 64 & 2,59 & 2,21 & 2,98 & 1,550 \\
\hline Deixou queimar a espátula com um fósforo. & 64 & 2,55 & 2,20 & 2,90 & 1,402 \\
\hline
\end{tabular}




\begin{tabular}{|c|c|c|c|c|c|}
\hline \multirow[b]{3}{*}{ Descrição comportamental } & \multirow{2}{*}{\multicolumn{5}{|c|}{$\begin{array}{c}\text { Cozinheiro } \\
\text { Int. conf. 95\% }\end{array}$}} \\
\hline & & & & & \\
\hline & $N$ & $M$ & $L I$ & $L S$ & $D P$ \\
\hline Partiu os copos todos. & 64 & 2,30 & 1,94 & 2,65 & 1,433 \\
\hline Trocou açúcar por sal e estragou a sobremesa. & 64 & 2,22 & 1,90 & 2,53 & 1,266 \\
\hline Deixou cair o chapéu para o fogão aceso e o chapéu incendiou. & 64 & 2,19 & 1,90 & 2,47 & 1,139 \\
\hline Pegou fogo à cozinha. & 64 & 1,89 & 1,58 & 2,20 & 1,236 \\
\hline
\end{tabular}

Nota. Comportamentos a negrito são típicos de Cozinheiro para 95\% de confiança; $N$ (número de respostas), $M$ (média da avaliação), $D P$ (desvio padrão), $L I$ (limite inferior), $L S$ (limite superior).

Quadro 4

Resultados obtidos na profissão Médico

\begin{tabular}{|c|c|c|c|c|c|}
\hline \multirow[b]{3}{*}{ Descrição comportamental } & \multicolumn{5}{|c|}{ Médico } \\
\hline & \multicolumn{5}{|c|}{ Int. conf. $95 \%$} \\
\hline & $N$ & $M$ & $L I$ & $L S$ & $D P$ \\
\hline Estudou durante muitos anos para se tornar médico. & 58 & 8,26 & 7,97 & 8,55 & 1,101 \\
\hline Colocou a touca e a máscara antes de entrar no bloco operatório. & 58 & 8,03 & 7,67 & 8,40 & 1,389 \\
\hline Receitou uma caixa de comprimidos a uma senhora idosa. & 58 & 7,97 & 7,53 & 8,40 & 1,665 \\
\hline Teve de ficar de serviço à noite no hospital. & 58 & 7,95 & 7,65 & 8,25 & 1,130 \\
\hline Analisou exames médicos. & 58 & 7,84 & 7,49 & 8,20 & 1,361 \\
\hline Prescreveu exames médicos. & 58 & 7,84 & 7,47 & 8,22 & 1,424 \\
\hline Examinou a garganta com a espátula. & 58 & 7,83 & 7,49 & 8,17 & 1,300 \\
\hline Passou uma receita com uma letra ilegível. & 58 & 7,83 & 7,52 & 8,14 & 1,172 \\
\hline Realizou uma cirurgia de várias horas. & 58 & 7,59 & 7,22 & 7,95 & 1,377 \\
\hline Analisou as radiografias do paciente. & 58 & 7,53 & 7,18 & 7,89 & 1,366 \\
\hline Pediu ao paciente para se deitar na maca para o examinar. & 58 & 7,43 & 6,97 & 7,90 & 1,768 \\
\hline Frequentou uma reunião com a direcção do hospital. & 58 & 7,40 & 7,04 & 7,75 & 1,350 \\
\hline Foi a uma conferência sobre medicina interna. & 58 & 7,31 & 6,93 & 7,69 & 1,429 \\
\hline Examinou o olho do paciente com uma lanterna especial. & 58 & 7,16 & 6,68 & 7,63 & 1,804 \\
\hline Mediu a tensão arterial ao doente. & 58 & 7,12 & 6,61 & 7,64 & 1,956 \\
\hline Colocou a bata e as luvas antes de analisar os pacientes. & 58 & 6,98 & 6,50 & 7,47 & 1,840 \\
\hline Lavou as mãos com um gel desinfectante para tratar de um paciente. & 58 & 6,95 & 6,46 & 7,43 & 1,849 \\
\hline Verificou se o paciente tinha febre usando um termómetro. & 58 & 6,90 & 6,25 & 7,54 & 2,454 \\
\hline Cobrou uma verdadeira fortuna pela operação. & 58 & 6,86 & 6,43 & 7,30 & 1,659 \\
\hline Auscultou um paciente asmático com um estetoscópio. & 58 & 6,84 & 6,32 & 7,37 & 1,981 \\
\hline Lê livros e artigos científicos para se manter actualizado. & 58 & 6,84 & 6,32 & 7,37 & 1,998 \\
\hline Diagnosticou com eficácia a doença do cliente. & 57 & 6,84 & 6,45 & 7,24 & 1,486 \\
\hline Leu os resultados das análises ao paciente e comunicou-lhe as conclusões. & 58 & 6,83 & 6,33 & 7,33 & 1,893 \\
\hline Utilizou um bisturi para fazer uma incisão na barriga. & 58 & 6,74 & 6,30 & 7,18 & 1,671 \\
\hline Com uma seringa, anestesiou paciente. & 58 & 6,67 & 6,07 & 7,27 & 2,289 \\
\hline Deixou os pacientes mais de duas horas à espera para a consulta. & 58 & 6,57 & 6,06 & 7,07 & 1,920 \\
\hline Chegou atrasado à consulta. & 58 & 6,53 & 5,95 & 7,12 & 2,218 \\
\hline Esclareceu o paciente sobre a sua doença. & 58 & 6,33 & 5,83 & 6,82 & 1,877 \\
\hline
\end{tabular}


$(\leftarrow$ cont. $)$

\begin{tabular}{|c|c|c|c|c|c|}
\hline \multirow[b]{3}{*}{ Descrição comportamental } & \multicolumn{5}{|c|}{ Médico } \\
\hline & \multicolumn{5}{|c|}{ Int. conf. $95 \%$} \\
\hline & $N$ & $M$ & $L I$ & $L S$ & $D P$ \\
\hline Pediu opinião a outro especialista quanto ao tratamento a aplicar. & 58 & 6,21 & 5,81 & 6,61 & 1,519 \\
\hline Ligou o pulso de um adolescente. & 58 & 6,16 & 5,75 & 6,56 & 1,542 \\
\hline Utilizou agulha e linha para coser a ferida. & 58 & 6,07 & 5,53 & 6,60 & 2,034 \\
\hline Utilizou uma linguagem incompreensível ao falar com um doente. & 58 & 6,02 & 5,59 & 6,45 & 1,628 \\
\hline Colocou um penso rápido depois de retirar sangue ao doente. & 58 & 5,91 & 5,23 & 6,60 & 2,611 \\
\hline Fez uma ressonância magnética ao um doente. & 58 & 5,88 & 5,25 & 6,51 & 2,385 \\
\hline Escutou atentamente as queixas de um paciente. & 58 & 5,74 & 5,27 & 6,22 & 1,802 \\
\hline Utilizou cotonetes para retirar uma amostra de saliva do paciente. & 58 & 5,71 & 5,10 & 6,32 & 2,317 \\
\hline Foi antipático para um doente. & 58 & 5,62 & 5,25 & 6,00 & 1,424 \\
\hline Não explicou convenientemente a doença ao seu paciente. & 58 & 5,62 & 5,18 & 6,06 & 1,663 \\
\hline Não informou o doente de todas as possibilidades de tratamento. & 58 & 5,38 & 4,93 & 5,83 & 1,725 \\
\hline Vacinou uma criança. & 57 & 5,30 & 4,63 & 5,97 & 2,528 \\
\hline Aplicou uma pomada num eczema. & 57 & 5,25 & 4,61 & 5,88 & 2,393 \\
\hline Deu três colheres de xarope ao um bebé muito constipado. & 58 & 4,83 & 4,24 & 5,41 & 2,217 \\
\hline "Leva" os problemas dos pacientes para casa. & 58 & 4,67 & 4,11 & 5,23 & 2,139 \\
\hline Preparou a injecção para o doente. & 58 & 4,67 & 4,03 & 5,31 & 2,431 \\
\hline Fez um diagnóstico incorrecto. & 58 & 4,62 & 4,21 & 5,03 & 1,565 \\
\hline Colocou o gesso muito apertado. & 58 & 4,59 & 4,11 & 5,06 & 1,816 \\
\hline Não explicou os efeitos secundários da operação. & 58 & 4,55 & 4,03 & 5,07 & 1,975 \\
\hline Espetou mal a seringa ao dar a anestesia e provocou um hematoma. & 58 & 4,36 & 3,85 & 4,88 & 1,962 \\
\hline Coseu mal o paciente e deixou-lhe uma grande cicatriz. & 58 & 4,33 & 3,88 & 4,78 & 1,711 \\
\hline Analisou mal o raio- $X$. & 58 & 4,29 & 3,79 & 4,80 & 1,929 \\
\hline Adormeceu durante o banco e não compareceu a uma urgência. & 58 & 4,26 & 3,72 & 4,80 & 2,065 \\
\hline Perdeu o estetoscópio. & 55 & 4,11 & 3,58 & 4,63 & 1,941 \\
\hline Prescreveu o antibiótico errado. & 57 & 4,04 & 3,55 & 4,52 & 1,832 \\
\hline Mesmo estando com gripe não usou máscara durante as consultas. & 57 & 3,98 & 3,40 & 4,56 & 2,183 \\
\hline Cortou uma veia do doente durante a cirurgia. & 56 & 3,98 & 3,49 & 4,48 & 1,844 \\
\hline Não se actualiza e exerce uma medicina obsoleta. & 58 & 3,90 & 3,36 & 4,44 & 2,058 \\
\hline Engasgou um paciente com uma espátula. & 58 & 3,84 & 3,24 & 4,45 & 2,300 \\
\hline Esqueceu-se de pedir análises ao sangue. & 58 & 3,64 & 3,16 & 4,11 & 1,813 \\
\hline Trocou as análises dos doentes. & 58 & 3,55 & 3,15 & 3,96 & 1,547 \\
\hline Não utilizou material bem esterilizado & 58 & 3,34 & 2,88 & 3,81 & 1,782 \\
\hline Esqueceu-se da sua maleta de médico em casa. & 58 & 3,33 & 2,85 & 3,81 & 1,820 \\
\hline Ao retirar sangue fez mal o garrote. & 58 & 3,21 & 2,75 & 3,66 & 1,725 \\
\hline Recusou-se a tratar um doente com sida. & 58 & 3,16 & 2,67 & 3,64 & 1,862 \\
\hline Não utilizou pensos para cobrir uma ferida que acabou por infectar. & 58 & 3,12 & 2,68 & 3,56 & 1,666 \\
\hline Enganou-se três vezes a passar a receita. & 58 & 3,07 & 2,62 & 3,52 & 1,726 \\
\hline Esqueceu-se da tesoura dentro do corpo do doente. & 57 & 2,81 & 2,30 & 3,32 & 1,922 \\
\hline Procedeu à remoção de um órgão errado. & 58 & 2,38 & 1,96 & 2,80 & 1,599 \\
\hline Utilizou uma compressa para a qual espirrou. & 58 & 2,19 & 1,81 & 2,57 & 1,456 \\
\hline Não desinfectou as mãos antes da operação. & 57 & 2,07 & 1,67 & 2,47 & 1,498 \\
\hline Limpou uma ferida com uma gaze já usada. & 58 & 1,86 & 1,51 & 2,22 & 1,357 \\
\hline
\end{tabular}

Nota. Comportamentos a negrito são típicos de Médico para $95 \%$ de confiança; $N$ (número de respostas), $M$ (média da avaliação), $D P$ (desvio padrão), LI (limite inferior), LS (limite superior). 
Quadro 5

Resultados obtidos na profissão Músico

\begin{tabular}{|c|c|c|c|c|c|}
\hline \multirow[b]{3}{*}{ Descrição comportamental } & \multicolumn{5}{|c|}{ Músico } \\
\hline & \multicolumn{5}{|c|}{ Int. conf. $95 \%$} \\
\hline & $N$ & $M$ & $L I$ & $L S$ & $D P$ \\
\hline Afinou o seu instrumento musical. & 58 & 8,16 & 7,80 & 8,51 & 1,348 \\
\hline Sabe ler bem uma pauta musical. & 57 & 7,88 & 7,51 & 8,24 & 1,377 \\
\hline Guarda o seu instrumento cuidadosamente. & 58 & 7,78 & 7,51 & 8,05 & 1,027 \\
\hline Ensaia muitas horas por dia. & 57 & 7,40 & 7,05 & 7,76 & 1,334 \\
\hline Comprou palhetas novas para a guitarra. & 58 & 7,40 & 7,04 & 7,75 & 1,363 \\
\hline Organizou as partituras. & 57 & 7,23 & 6,85 & 7,60 & 1,414 \\
\hline Costuma andar com um instrumento às costas. & 58 & 7,21 & 6,83 & 7,58 & 1,424 \\
\hline Comprou cordas novas para o violino. & 58 & 7,09 & 6,64 & 7,53 & 1,689 \\
\hline Passou a tarde a gravar no estúdio com outros músicos. & 58 & 7,07 & 6,66 & 7,48 & 1,554 \\
\hline Tem uma enorme coleç̧ão de CD’s e de discos de vinil. & 58 & 6,91 & 6,47 & 7,36 & 1,699 \\
\hline Foi aplaudido de pé. & 58 & 6,90 & 6,53 & 7,27 & 1,410 \\
\hline Não gosta que as pessoas falem enquanto toca. & 58 & 6,83 & 6,40 & 7,26 & 1,634 \\
\hline Conhece muitos músicos e muitas orquestras. & 57 & 6,79 & 6,36 & 7,22 & 1,612 \\
\hline Dá aulas de música. & 58 & 6,78 & 6,35 & 7,20 & 1,601 \\
\hline Limpou o instrumento após utilizá-lo. & 58 & 6,72 & 6,31 & 7,14 & 1,587 \\
\hline Cumprimentou a audiência pelo microfone. & 58 & 6,71 & 6,19 & 7,23 & 1,974 \\
\hline Mandou afinar o piano. & 58 & 6,69 & 6,22 & 7,16 & 1,779 \\
\hline Comove as pessoas com as suas melodias. & 58 & 6,57 & 6,16 & 6,98 & 1,568 \\
\hline Fez muitas escalas na fase de aquecimento antes do concerto. & 58 & 6,55 & 6,14 & 6,97 & 1,580 \\
\hline Tocou a sua música favorita na abertura de um concerto. & 58 & 6,48 & 6,00 & 6,96 & 1,828 \\
\hline Estudou solfejo para ter uma melhor formação musical. & 57 & 6,26 & 5,74 & 6,79 & 1,969 \\
\hline Usou uma viola para compor uma melodia triste. & 58 & 6,22 & 5,81 & 6,64 & 1,568 \\
\hline Dedicou a música aos familiares. & 58 & 6,22 & 5,78 & 6,66 & 1,676 \\
\hline Seguiu à risca as instruções do maestro. & 58 & 6,19 & 5,69 & 6,69 & 1,905 \\
\hline Chorou de emoção quando ouviu aquela música. & 58 & 5,98 & 5,49 & 6,48 & 1,878 \\
\hline Ganhou um concurso de músicos profissionais. & 58 & 5,97 & 5,51 & 6,42 & 1,727 \\
\hline Anda constantemente a ouvir mp3. & 58 & 5,67 & 5,15 & 6,19 & 1,986 \\
\hline Deu alguns autógrafos. & 57 & 5,61 & 5,14 & 6,09 & 1,780 \\
\hline É um dos solistas mais reputados da orquestra. & 58 & 5,53 & 5,09 & 5,98 & 1,678 \\
\hline Aprecia ópera. & 58 & 5,50 & 5,12 & 5,88 & 1,430 \\
\hline Interessa-se por todos os tipos de música. & 58 & 5,31 & 4,84 & 5,78 & 1,779 \\
\hline Rabisca partituras escrevendo lembretes importantes. & 58 & 5,31 & 4,74 & 5,89 & 2,186 \\
\hline Marca sempre o ritmo com uma batuta. & 58 & 5,03 & 4,56 & 5,51 & 1,796 \\
\hline Gritou quando um dos seus alunos não tocou a nota certa. & 58 & 4,59 & 4,11 & 5,07 & 1,826 \\
\hline Durante o concerto a corda do violino partiu-se. & 58 & 4,48 & 3,99 & 4,98 & 1,875 \\
\hline Desafinou no ensaio com a orquestra. & 58 & 4,45 & 4,00 & 4,90 & 1,719 \\
\hline Foi a um concerto e disse mal de todos os músicos. & 58 & 4,43 & 3,85 & 5,01 & 2,209 \\
\hline Cortou um dedo numa corda do seu instrumento. & 58 & 4,38 & 3,80 & 4,96 & 2,207 \\
\hline Comprou uma harpa. & 57 & 4,30 & 3,77 & 4,83 & 2,009 \\
\hline Nunca deu concertos a solo. & 58 & 4,29 & 3,88 & 4,70 & 1,556 \\
\hline Não aceitou o convite de outros músicos para formar uma banda. & 58 & 4,24 & 3,83 & 4,66 & 1,582 \\
\hline Aprendeu a tocar piano antes dos 3 anos de idade. & 58 & 4,09 & 3,64 & 4,54 & 1,709 \\
\hline Chegou atrasado ao auditório no dia concerto. & 57 & 4,02 & 3,48 & 4,55 & 2,022 \\
\hline Esqueceu-se de fazer uma vénia para a audiência no final do concerto. & 58 & 4,02 & 3,51 & 4,52 & 1,915 \\
\hline
\end{tabular}


$(\leftarrow$ cont. $)$

\begin{tabular}{|c|c|c|c|c|c|}
\hline \multirow[b]{3}{*}{ Descrição comportamental } & \multicolumn{5}{|c|}{ Músico } \\
\hline & \multicolumn{5}{|c|}{ Int. conf. 95\% } \\
\hline & $N$ & $M$ & $L I$ & $L S$ & $D P$ \\
\hline Plagiou o trabalho de outro músico. & 58 & 3,95 & 3,45 & 4,45 & 1,905 \\
\hline Achou que a formação em canto coral era uma perda de tempo. & 58 & 3,90 & 3,47 & 4,33 & 1,640 \\
\hline Reproduziu de forma incorrecta o que estava na pauta musical. & 58 & 3,84 & 3,36 & 4,33 & 1,862 \\
\hline Recusou-se a ter mais aulas de piano. & 56 & 3,79 & 3,32 & 4,25 & 1,724 \\
\hline Não cumpriu a agenda de concertos. & 58 & 3,64 & 3,17 & 4,10 & 1,764 \\
\hline Compôs 10 músicas numa semana. & 58 & 3,62 & 3,12 & 4,12 & 1,918 \\
\hline Esqueceu-se da pauta de música. & 57 & 3,56 & 3,05 & 4,07 & 1,927 \\
\hline Estragou uma flauta, deixando-a cair no chão. & 58 & 3,52 & 3,10 & 3,94 & 1,603 \\
\hline Não ensaiou o suficiente antes do concerto. & 58 & 3,50 & 3,10 & 3,90 & 1,513 \\
\hline Perdeu as pautas das músicas. & 58 & 3,47 & 3,00 & 3,93 & 1,779 \\
\hline Esqueceu-se de passar a melodia para a partitura. & 58 & 3,43 & 2,94 & 3,93 & 1,884 \\
\hline Esqueceu-se do violino no carro. & 57 & 3,40 & 2,88 & 3,92 & 1,963 \\
\hline Faltou aos ensaios para o musical. & 58 & 3,38 & 2,94 & 3,81 & 1,653 \\
\hline Não conseguiu subir ao palco porque estava muito ansioso. & 58 & 3,36 & 2,90 & 3,82 & 1,754 \\
\hline Compôs uma música sem qualquer harmonia. & 58 & 3,36 & 2,89 & 3,83 & 1,794 \\
\hline Fez má figura a tocar saxofone. & 58 & 3,36 & 2,93 & 3,79 & 1,640 \\
\hline Esqueceu-se de utilizar o microfone durante o concerto. & 58 & 3,22 & 2,68 & 3,76 & 2,052 \\
\hline Recusou-se a ir com a orquestra em digressão pelo país. & 58 & 3,14 & 2,70 & 3,57 & 1,648 \\
\hline Deixou cair o violino. & 58 & 3,05 & 2,69 & 3,42 & 1,395 \\
\hline Enganou-se várias vezes numa música durante um espectáculo. & 58 & 3,03 & 2,68 & 3,39 & 1,363 \\
\hline Não tocou a parte da música que lhe competia na orquestra. & 58 & 3,02 & 2,56 & 3,48 & 1,742 \\
\hline Deixou cair as partituras numa poça de água. & 58 & 2,90 & 2,55 & 3,25 & 1,334 \\
\hline Perdeu o seu arco de violino mais precioso. & 58 & 2,90 & 2,53 & 3,27 & 1,410 \\
\hline Irritou-se e pontapeou a bateria de um colega de orquestra. & 58 & 2,72 & 2,28 & 3,16 & 1,673 \\
\hline Não afinou o violino antes do concerto. & 58 & 2,59 & 2,16 & 3,01 & 1,623 \\
\hline Não sentiu qualquer emoção quando estava a tocar. & 58 & 2,52 & 2,10 & 2,94 & 1,603 \\
\hline
\end{tabular}

Nota. Comportamentos a negrito são típicos de Músico para $95 \%$ de confiança; $N$ (número de respostas), $M$ (média da avaliação), $D P$ (desvio padrão), $L I$ (limite inferior), LS (limite superior).

Quadro 6

Resultados obtidos na profissão Agricultor

\begin{tabular}{lccccc}
\hline & \multicolumn{4}{c}{ Agricultor } \\
\cline { 2 - 6 } & \multicolumn{4}{c}{ Int. conf. 95\% } \\
\cline { 2 - 6 } Descrição comportamental & $N$ & $M$ & $L I$ & $L S$ & $D P$ \\
\hline Levantou-se de madrugada e foi para o campo trabalhar. & 58 & 8,02 & 7,76 & 8,28 &, 982 \\
Tem as mãos calejadas de trabalhar muito. & 58 & 7,97 & 7,65 & 8,28 & 1,199 \\
Arou a terra para semear novamente. & 58 & 7,91 & 7,60 & 8,23 & 1,189 \\
Cavou a terra com uma enxada. & 58 & 7,66 & 7,35 & 7,96 & 1,148 \\
Alimentou os animais logo de manhã. & 58 & 7,57 & 7,19 & 7,95 & 1,440 \\
Andou no tractor a verificar o terreno. & 58 & 7,52 & 7,12 & 7,92 & 1,513 \\
Ordenhou as vacas logo pela manhã e encheu as vasilhas de leite. & 58 & 7,47 & 7,09 & 7,84 & 1,417 \\
Fez um espantalho para afugentar os pássaros. & 58 & 7,47 & 7,08 & 7,85 & 1,466 \\
Acartou com uma saca de milho para as galinhas. & 58 & 7,45 & 7,01 & 7,89 & 1,667 \\
\hline & & & & & (cont. $\rightarrow$ )
\end{tabular}




\begin{tabular}{|c|c|c|c|c|c|}
\hline \multirow[b]{3}{*}{ Descrição comportamental } & \multicolumn{5}{|c|}{ Agricultor } \\
\hline & \multicolumn{5}{|c|}{ Int. conf. $95 \%$} \\
\hline & $N$ & $M$ & $L I$ & $L S$ & $D P$ \\
\hline Trabalha muitas horas e tem baixos rendimentos. & 58 & 7,41 & 7,01 & 7,82 & 1,545 \\
\hline Planta uma variedade de vegetais ou árvores de fruta. & 58 & 7,33 & 6,90 & 7,76 & 1,637 \\
\hline Utilizou um balde para colocar as uvas. & 57 & 7,28 & 6,93 & 7,63 & 1,320 \\
\hline Recolheu os ovos da capoeira e meteu-os numa cesta. & 58 & 7,24 & 6,82 & 7,67 & 1,615 \\
\hline Empilhou o feno com uma forquilha. & 58 & 7,24 & 6,86 & 7,62 & 1,443 \\
\hline Passou o dia ao sol e tem a pele queimada. & 58 & 7,24 & 6,87 & 7,61 & 1,418 \\
\hline Transportou as sacas de adubo num carro de mão. & 58 & 7,10 & 6,70 & 7,50 & 1,518 \\
\hline Sujou as botas todas com bosta de vaca. & 58 & 7,02 & 6,56 & 7,47 & 1,722 \\
\hline Cortou o trigo com uma debulhadora. & 58 & 7,00 & 6,51 & 7,49 & 1,845 \\
\hline Calçou as botas adequadas para a lama. & 58 & 6,98 & 6,53 & 7,44 & 1,732 \\
\hline Subiu a um escadote e apanhou as laranjas da árvore. & 58 & 6,93 & 6,50 & 7,36 & 1,642 \\
\hline Podou cuidadosamente a vinha com uma tesoura de podar. & 58 & 6,88 & 6,37 & 7,39 & 1,947 \\
\hline Utilizou um regador para regar as alfaces. & 58 & 6,76 & 6,30 & 7,22 & 1,750 \\
\hline Regou os vegetais com uma mangueira. & 58 & 6,76 & 6,28 & 7,24 & 1,819 \\
\hline Deita-se muito cedo. & 58 & 6,74 & 6,23 & 7,25 & 1,934 \\
\hline Pegou no machado e cortou uma grande pilha de lenha. & 58 & 6,66 & 6,11 & 7,20 & 2,057 \\
\hline Deu os restolhos aos animais. & 58 & 6,64 & 6,20 & 7,08 & 1,672 \\
\hline Apanhou algumas batatas para cozer para o almoço. & 58 & 6,55 & 6,12 & 6,99 & 1,656 \\
\hline Com uma picareta abriu um rego para a água passar. & 58 & 6,43 & 5,91 & 6,95 & 1,966 \\
\hline Espetou uma farpa do cabo da enxada. & 58 & 6,40 & 5,88 & 6,91 & 1,955 \\
\hline Utilizou o ancinho para arrancar raízes. & 58 & 6,40 & 5,88 & 6,91 & 1,955 \\
\hline Arranjou uma cerca partida pregando novas tábuas. & 58 & 6,36 & 5,87 & 6,86 & 1,889 \\
\hline Comprou novas ferramentas. & 57 & 6,25 & 5,84 & 6,65 & 1,527 \\
\hline Pulverizou o pomar com pesticidas. & 58 & 6,17 & 5,70 & 6,64 & 1,788 \\
\hline Usou a motosserra para cortar os pinheiros. & 57 & 6,14 & 5,58 & 6,70 & 2,100 \\
\hline Fez o parto de um vitelinho. & 58 & 6,05 & 5,52 & 6,58 & 2,012 \\
\hline Utilizou uma foice para cortar ervas daninhas. & 57 & 6,00 & 5,43 & 6,57 & 2,163 \\
\hline É uma pessoa com pouca instrução. & 58 & 5,83 & 5,30 & 6,35 & 2,001 \\
\hline Não vendeu todo o stock de vegetais. & 58 & 5,79 & 5,27 & 6,31 & 1,980 \\
\hline Pegou na pá para recolher os frutos secos da eira. & 58 & 5,71 & 5,21 & 6,20 & 1,883 \\
\hline Arranhou-se todo perto das silvas. & 58 & 5,59 & 5,02 & 6,15 & 2,144 \\
\hline Cortou-se com a tesoura de podar. & 58 & 5,53 & 4,93 & 6,14 & 2,296 \\
\hline Cultiva alimentos biológicos. & 58 & 5,43 & 4,92 & 5,94 & 1,939 \\
\hline Trilhou a mangueira com uma máquina agrícola. & 57 & 5,30 & 4,74 & 5,85 & 2,096 \\
\hline Esqueceu-se da máscara quando foi pulverizar. & 58 & 4,98 & 4,35 & 5,62 & 2,417 \\
\hline Esqueceu-se do balde com o adubo no celeiro. & 57 & 4,70 & 4,20 & 5,20 & 1,889 \\
\hline Não usou chapéu e apanhou uma insolação. & 58 & 4,60 & 4,04 & 5,17 & 2,152 \\
\hline Caiu de um escadote durante a apanha da azeitona. & 58 & 4,59 & 4,03 & 5,14 & 2,120 \\
\hline Levou com o ancinho na perna. & 58 & 4,43 & 3,89 & 4,97 & 2,053 \\
\hline Cortou-se com uma foice. & 58 & 4,29 & 3,82 & 4,76 & 1,787 \\
\hline Perdeu o controlo do tractor e teve um acidente. & 57 & 3,96 & 3,52 & 4,41 & 1,690 \\
\hline Deixou cair uma cesta cheia de ovos. & 58 & 3,69 & 3,23 & 4,15 & 1,739 \\
\hline Não meteu gasóleo no tractor. & 57 & 3,60 & 3,13 & 4,06 & 1,741 \\
\hline Colheu a fruta ainda muito verde. & 57 & 3,40 & 2,99 & 3,82 & 1,557 \\
\hline Pisou a pá e levou com o cabo na cara. & 57 & 3,39 & 2,88 & 3,90 & 1,925 \\
\hline Deixou os morangos ao sol dentro do carro de mão. & 57 & 3,35 & 2,92 & 3,78 & 1,609 \\
\hline
\end{tabular}




\begin{tabular}{|c|c|c|c|c|c|}
\hline \multirow[b]{3}{*}{ Descrição comportamental } & \multicolumn{5}{|c|}{ Agricultor } \\
\hline & \multicolumn{5}{|c|}{ Int. conf. $95 \%$} \\
\hline & $N$ & $M$ & $L I$ & $L S$ & $D P$ \\
\hline Foi podar folhas velhas mas cortou imensas raízes. & 58 & 3,31 & 2,84 & 3,78 & 1,789 \\
\hline Pisou sem querer as sementes acabadas de cultivar. & 58 & 3,31 & 2,86 & 3,76 & 1,698 \\
\hline Deixou as ferramentas à chuva que enferrujaram. & 58 & 3,28 & 2,83 & 3,72 & 1,704 \\
\hline Não tomou banho depois de um dia a cavar. & 57 & 3,19 & 2,69 & 3,70 & 1,913 \\
\hline Deixou apodrecer as sementes dentro das sacas. & 58 & 2,98 & 2,53 & 3,44 & 1,732 \\
\hline Espalhou tanto pesticida que queimou as vinhas. & 58 & 2,86 & 2,49 & 3,24 & 1,432 \\
\hline Não levou as vasilhas de água para dar aos animais. & 58 & 2,81 & 2,41 & 3,21 & 1,515 \\
\hline Cavou em cima de plantas que tinha semeado e deu cabo das raízes. & 58 & 2,76 & 2,30 & 3,22 & 1,760 \\
\hline Não se preocupa com as mudanças climáticas. & 57 & 2,75 & 2,25 & 3,25 & 1,883 \\
\hline Não sabe conduzir uma máquina agrícola. & 58 & 2,71 & 2,34 & 3,07 & 1,377 \\
\hline Tanto regou os morangos que estes apodreceram. & 58 & 2,71 & 2,34 & 3,08 & 1,414 \\
\hline Esqueceu-se de regar a horta. & 58 & 2,62 & 2,19 & 3,05 & 1,642 \\
\hline Não come aquilo que produz. & 58 & 2,59 & 2,18 & 2,99 & 1,545 \\
\hline Prendeu a cerca apenas com cordas e deixou fugir os animais. & 58 & 2,50 & 2,20 & 2,80 & 1,158 \\
\hline Assustou-se muito com um espantalho que ele próprio tinha colocado. & 57 & 2,49 & 2,06 & 2,92 & 1,616 \\
\hline
\end{tabular}

Nota. Comportamentos a negrito são típicos de Agricultor para 95\% de confiança; $N$ (número de respostas), $M$ (média da avaliação), $D P$ (desvio padrão), $L I$ (limite inferior), $L S$ (limite superior).

\section{Discussão}

O presente artigo apresenta dois estudos realizados com o objectivo de desenvolver e avaliar um conjunto de descrições comportamentais típicas de seis grupos profissionais. Por este meio tentamos responder a uma necessidade empírica de obter descrições comportamentais de grupos alvo diversos, que sejam específicas das suas ocupações profissionais fazendo ainda referência a situações, e tarefas do alvo e ainda incluir objectos, utensílios ou ferramentas que ilustrem o contexto no qual estas acções são executadas.

Este tipo de material estímulo poderá permitir o estudo dos processos de formação de impressões no âmbito de uma abordagem situada e corporalizada da cognição. Esta proposta, não rejeitando a importância das operações simbólicas na interpretação da experiência, sugere que quando uma experiência ocorre, o cérebro captura os estados nas modalidades e integra-os numa única representação multimodal armazenada em memória. Mais tarde, quando o conhecimento é necessário para representar uma categoria, e na ausência da entidade ou situação (offline), as representações multimodais (i.e., símbolos perceptivos) capturadas durante a experiência, são reactivadas para simular como o cérebro representou a percepção, a acção e a introspecção associadas originalmente (Barsalou, 1999; ver Barsalou, 2008, para uma revisão). Com base nestas propostas assumimos que a cognição, incluindo os processos de formação de impressões e de julgamento social serão melhor compreendidos se não forem dissociados dos elementos sensório-motores e contextuais que incorporam.

Este tipo de descrições comportamentais poderão ser também úteis em duas áreas específicas, designadamente estudos das neurociências cognitivas e estudos de memória de acção. No que diz respeito à primeira área de estudo mencionada, ela refere-se às tentativas de mostrar a existência de associações funcionais específicas entre sistemas de acção e de linguagem durante o processamento 
lexical. Estas propostas encontram apoio empírico em alguns estudos que mostram que quer movimentos isolados e repetitivos de partes únicas do corpo quer a leitura silenciosa de palavras ou frases incluindo verbos de acção activam áreas semelhantes do córtex motor e pré motor (Hauk, Johnsrude, \& Pulvermüller, 2004; Tettamanti et al., 2005). Por outro lado, a estimulação de áreas motoras do cérebro em participantes enquanto estes realizam tarefas de decisão lexical sobre palavras ou frases envolvendo acções motoras revelou decisões lexicais mais rápidas relativamente a estímulos relacionados com a área motora estimulada (e.g., Pulvermüller, 2008; Pulvermüller, Hauk, Nikulin, \& Ilmoniemi, 2005). A realização destes estudos que indicam que representações de acção específicas são activadas durante a compreensão de palavras ou frases envolvendo acções poderá assim beneficiar do desenvolvimento de material estímulo onde essas acções específicas sejam incorporadas. Por outro lado, os estudos de memória de acção, populares a partir da década de 80 (e.g., Cohen, 1981; Engelkamp \& Krumnacker, 1980; Saltz \& Donnerwerth, 1981; ver Roediger \& Zaromb, 2010, para uma revisão) têm vindo a revelar um melhor desempenho mnésico em tarefas que implicam a realização de uma acção por parte do participante, em comparação com tarefas verbais. As explicações apontadas para este efeito não são consensuais (e.g., Bäckman \& Nilsson, 1984, 1985; Cohen, 1981, 1983; Engelkamp \& Zimmer, 1984, 1985; ver Roediger \& Zaromb, 2010, para uma revisão) levando alguns autores a sugerir (e.g., Freitas \& Albuquerque, 2007a,b) que algumas das inconsistências encontradas se podem dever às diferentes características das listas de itens estímulo utilizadas. Neste sentido os autores avançam com a validação de um conjunto de estímulos avaliados nas dimensões de familiaridade, emocionalidade e envolvimento motor. No entanto, estas normas não se adequam a tarefas de formação de impressões na medida em que incidem, sobretudo, sobre descrições simples de comportamentos motores (e.g., "registar uma morada", "balançar uma caneta") a partir dos quais não é possível inferir traços ou formar impressões de personalidade. Neste sentido, os estudos de formação de impressões onde se pretenda explorar os efeitos de descrições comportamentais de acções concretas realizadas ou imaginadas, poderão beneficiar de material estímulo que veicule informação mais específica acerca do comportamento do alvo social em questão.

Tal como na generalidade dos pré-testes desta natureza, o conjunto de estímulos que aqui se apresenta encerra algumas limitações. Não podemos deixar de salientar por isso o facto de, não obstante as listas de estímulos incluírem itens de valência positiva e negativa, a valência não ter sido pré-testada. Poderíamos ainda ter obtido avaliações de outras dimensões, nomeadamente a familiaridade, e a actividade motora envolvidas nos comportamentos avaliados. No entanto a ausência de avaliações nestas dimensões adicionais fundamentou-se em dificuldades de ordem prática, e a sua inclusão exigiria ou a supressão de uma grande quantidade de descrições comportamentais da lista original ou um aumento muito significativo da amostra de participantes. Adicionalmente alertamos ainda para limitações relativas a uma utilização generalizada destes materiais a uma população mais alargada por um período de tempo indeterminado. Tal como referido na secção do método, a nossa amostra tem características particulares, designadamente a faixa etária, o nível cultural e possivelmente um conhecimento bastante heterogéneo das actividades tipicamente realizadas pelos membros dos grupos profissionais estudados. Todavia, pensamos que estas normas poderão ser utilizadas junto de uma população universitária, junto da qual, muitos dos estudos neste âmbito são realizados. Finalmente, a utilização desta base de estímulos não poderá ser dissociada do contexto social e temporal, na medida em que estes determinam mudanças nas actividades realizadas pelos membros dos grupos profissionais estudados e nos próprios instrumentos, ferramentas e utensílios que elas implicam.

Pensamos contudo que a base de estímulos obtida possa ser útil em investigações subsequentes na área da formação de impressões em geral, e na área da cognição corporalizada e situada em particular. A sua aplicação poderá ainda estender-se a ramos das neurociências que procuram paralelismos na activação cerebral decorrente da compreensão ou desempenho de acções motoras e 
ainda em estudos de memória de acção, designadamente na área da formação de impressões, onde a informação sobre acções concretas parece desempenhar um papel importante.

\section{Referências}

Anderson, J. R., \& Bower, G. H. (1973). Human associative memory. Washington, D.C.: Winston.

Anderson, N. H. (1965). Averaging versus adding as a stimulus-combination rule in impression formation. Journal of Experimental Psychology, 70, 394-400.

Allport, F. H., \& Allport, G. W. (1921). Personality traits: Their classification and measurement. Journal of Abnormal and Social Psychology, 16, 6-40.

Asch, S. E. (1946). Forming impressions of personality. Journal of Abnormal and Social Psychology, 41, 258-290.

Bäckman, L., \& Nilsson, L.-G. (1984). Aging effects in free recall: An exception to the rule. Human Learning, 3, 53-69.

Bäckman, L., \& Nilsson, L.-G. (1985). Prerequisites for lack of age differences on memory performance. Experimental Aging Research, 11, 67-73.

Barsalou, L. W. (1999). Perceptual symbol systems. Behavioral and Brain Sciences, 22, 577-609.

Barsalou, L. W. (2007). Continuing themes in the study of human knowledge: Associations, imagery, propositions, and situations. In M. A. Gluck, J. R. Anderson, \& S. M. Kosslyn (Eds.), Memory and mind: A festschrift for Gordon H. Bower (pp. 209-227). New Jersey: Lawrence Erlbaum Associates.

Barsalou, L. W. (2008). Grounding symbolic operations in the brain's modal systems. In G. R. Semin \& E. R. Smith (Eds.), Embodied grounding: Social, cognitive, affective, and neuroscientific approaches (pp. 9-42). New York: Cambridge University Press.

Cohen, R. L. (1981). On the generality of some memory laws. Scandinavian Journal of Psychology, 22, 267-281.

Cohen, R. L. (1983). The effect of encoding variables on the free recall of words and action events. Memory \& Cognition, 11, 573-582.

Collins, A. M., \& Loftus, E. F. (1975). A spreading-activation theory of semantic memory. Psychological Review, 82, 407-428.

Collins, A. M., \& Quillian, M. R. (1969). Retrieval time from semantic memory. Journal of Verbal Learning and Verbal Behavior, 8, 240-247.

Engelkamp, J., \& Krumnacker, H. (1980). Imagery and motor processes in the retention of verbal materials. Zeitschrift für experimentelle und angewandte Psychologie, 27, 511-533.

Engelkamp, J., \& Zimmer, H. D. (1984). Motor program information as a separable memory unit. Psychological Research, 46, 283-299.

Engelkamp, J., \& Zimmer, H. D. (1985). Motor programs and their relation to semantic memory. German Journal of Psychology, 9, 239-254.

Freitas, M. C., \& Albuquerque, P. B. (2007a). Normas de familiaridade, emocionalidade e actividade motora de acções. Laboratório de Psicologia, 5, 33-48. 
Freitas, M. C., \& Albuquerque, P. B. (2007b). Memórias para acções: Um estudo de prioridade de processamento numa tarefa de dupla codificação. Psicologia, Educação e Cultura, XI, 95-112.

Fuhrman, R., Bodenhausen, G., \& Lichtenstein, M. (1989). On the trait implications of social behaviours: Kindness, intelligence, goodness, and normality ratings for 400 behavioral statements. Behaviour Research, Methods, Instruments, \& Computers, 21, 587-597.

Garcia-Marques, L., \& Hamilton, D. L. (1996). Resolving the apparent discrepancy between the incongruency and the expectancy-based illusory correlation effects: The TRAP model. Journal of Personality and Social Psychology, 71, 845-860.

Garcia-Marques, L., Hamilton, D. L, \& Maddox, K. B. (2002). Exhaustive and heuristic retrieval processes in person cognition: Further tests of the TRAP model. Journal of Personality and Social Psychology, 82, 193-207.

Garrido, M. V., Garcia-Marques, L., \& Jerónimo, R. (2004). Aventureiros, religiosos, ecológicos e artísticos: Pré teste de descrições comportamentais. Laboratório de Psicologia, 2, 95-101.

Glenberg, A. M. (2008). Toward the integration of bodily states, language, and action. In G. R. Semin \& E. R. Smith (Eds.), Embodied grounding: Social, cognitive, affective, and neuroscientific approaches (pp. 43-70). New York: Cambridge University Press.

Hamilton, D. L. (1986). Person perception. In L. Berkowitz (Ed.), A survey of social psychology (pp. 135-162, 3rd ed.). New York: Holt, Rinehart \& Winston.

Hamilton, D. L, \& Zanna, M. P. (1974). Context effects in impression formation: Changes in connotative meaning. Journal of Personality and Social Psychology, 29, 649-654.

Hamilton, D. L., Katz, L. B., \& Leirer, V. O. (1980). Cognitive representation of personality impressions: Organizational processes in first impression formation. Journal of Personality and Social Psychology, 39, 1050-1063.

Hastie, R. (1980). Memory for behavioral information that confirms or contradicts a personality impression. In R. Hastie, T. M. Ostrom, R. S. Wyer Jr., D. L. Hamilton, \& D. E. Carlston (Eds.), Person memory: The cognitive basis of social perception (pp. 155-178). Hillsdale, NJ: Erlbaum.

Hastie, R., \& Kumar, P. A. (1979). Person memory: Personality traits as organizing principles in memory for behaviors. Journal of Personality and Social Psychology, 37, 25-38.

Hauk, O., Johnsrude, I., \& Pulvermüller, F. (2004). Somatotopic representation of action words in human motor and premotor cortex. Neuron, 41, 301-307.

Higgins, E. T., \& Rholes, W. S. (1976). Impression formation and role fulfillment: A "Holistic Reference" approach. Journal of Experimental Social Psychology, 12, 422-435.

Palma, T., Garrido, M. V., \& Semin, G. R. (2011). Grounding person memory in space: Does spatial anchoring of behaviors improve recall? European Journal of Social Psychology, 41, 275-280.

Pulvermüller, F. (2008). Brain embodiment of category-specific semantic memory circuits. In G. R. Semin \& E. R. Smith (Eds.), Embodied grounding: Social, cognitive, affective, and neuroscientific approaches (pp. 71-97). New York: Cambridge University Press.

Pulvermüller, F., Hauk, O., Nikulin, V., \& Ilmoniemi, R. J. (2005). Functional links between motor and language systems. European Journal of Neuroscience, 21, 793-797.

Roediger, H. L., \& Zaromb, F. M. (2010). Memory for actions: How different? In L. Bäckman \& L. Nyberg (Eds.), Aging, memory and the brain: Essays in honour of Lars-Göran Nilsson (pp. 2452). Hove, U.K.: Psychology Press 
Rosenberg, S., Nelson, C., \& Vivekananthan, P. S. (1968). A multidimensional approach to the structure of personality impressions. Journal of Personality and Social Psychology, 9, 283-294.

Saltz, E., \& Donnerwerth-Nolan, S. (1981). Does motoric imagery facilitate memory for sentences? A selective interference test. Journal of Verbal Learning and Verbal Behavior, 20, 322-332.

Schank, R. C. (1982). Dynamic memory: A theory of reminding and learning in computers and people. Cambridge University Press.

Semin, G. R., Garrido, M. V., \& Palma, T. A. (2011, in press). Socially situated cognition: Recasting social cognition as an emergent phenomenon. In S. Fiske \& N. Macrae (Eds.), The Cambridge Handbook of Social Cognition. Sage: California: Sevenoaks.

Semin, G. R., \& Garrido, M. V. (2011, in press). A systemic approach to impression formation: From verbal to multimodal processes. In J. Forgas, K. Fiedler, \& C. Sedikides (Eds.), Social thinking and interpersonal behavior.

Semin, G. R., \& Smith, E. R. (2008). Embodied grounding: Social, cognitive, affective, and neuroscientific approaches. Cambridge, USA: Cambridge University Press.

Smith, E. R. (1998). Mental representation and memory. In D. Gilbert, S. Fiske, \& G. Lindzey (Eds.), Handbook of social psychology (pp. 391-445, 4th ed.). McGraw-Hill.

Smith, E. R., \& Semin, G. R. (2004). Socially situated cognition: Cognition in its social context. Advances in Experimental Social Psychology, 36, 53-117.

Srull, T. K. (1981). Person memory: Some tests of associative storage and retrieval models. Journal of Experimental Psychology: Human Learning \& Memory, 7, 440-463.

Srull, T. K., Lichtenstein, M., \& Rothbart, M. (1985). Associative storage and retrieval processes in person memory. Journal of Experimental Psychology: Learning, Memory, and Cognition, 11, 316-345.

Tettamanti, M., Buccino, G., Saccuman, M. C., Gallese, V., Danna, M., Scifo, P., Fazio, F., Rizzolatti, G., Cappa, S. F., \& Perani, D. (2005). Listening to action-related sentences activates frontoparietal motor circuits. Journal of Cognitive Neuroscience, 17, 273-281.

Wilson, M. (2002). Six views of embodied cognition. Psychonomic Bulletin and Review, 9, 625-36.

Wyer, R. S., \& Srull, T. K. (1989). Memory and cognition in its social context. Hillsdale, NJ: Erlbaum.

Zanna, M. P., \& Hamilton, D. L. (1977). Further evidence for meaning change in impression formation. Journal of Experimental Social Psychology, 13, 224-238. 